\title{
Microstructural Study of the Heat-treated 17-4PH Stainless Steel Parts Prepared by Selective Laser Melting
}

\author{
Y. Sun ${ }^{1}$, M. Aindow ${ }^{1}$, R. J. Hebert ${ }^{1}$ \\ 1. Department of Materials Science and Engineering, Institute of Materials Science, University of \\ Connecticut, Storrs, CT, USA
}

Metal powder-bed additive manufacturing (AM) processes are very different from the conventional subtractive manufacturing methods, resulting in non-uniform microstructures and highly anisotropic material properties for the as-built parts. The microstructures of powder-bed AM processed samples can be affected significantly by various factors including beam energy density, beam speed, local heat transfer conditions, and scan strategy. In a study by Reafi et al. on AM parts prepared by Selective Laser Melting (SLM) using 17-4 precipitation hardenable (PH) stainless steel, it was reported that a nonequilibrium microstructure developed [1]. This microstructure exhibited a strong difference in texture components parallel and perpendicular to the build direction resulting from the very high cooling rates. The SLM-prepared as-built part also contained a substantial fraction of retained austenite, in contrast to wrought 17-4PH materials, which have a fully martensitic structure strengthened by fine $\mathrm{Cu}$-rich precipitates. In recent work by Cheruvathur et al., post-build heat treatments were applied to AM 174PH materials to obtain a more uniform microstructure and promote the precipitation of the $\mathrm{Cu}$-rich phase [2]. It is clearly important to understand the microstructural development during AM processing and during subsequent heat treatment. In this study, the effect of post-build heat treatments on SLM prepared $17-4 \mathrm{PH}$ as-built parts is studied in comparison to that of conventionally processed $17-4 \mathrm{PH}$.

A 3DSystems ProX-300 laser powder bed AM machine was used to fabricate the test specimens. The microstructures of as-built and solution-treated (annealed at $1040^{\circ} \mathrm{C}$ for 4 hours and air cooled) $17-4 \mathrm{PH}$ AM parts and solution-treated 17-4PH bar stock were studied. SEM and EBSD analyses were performed using a FEI Teneo-LoVac FEG-SEM equipped with an EDAX TEAM ${ }^{\mathrm{TM}}$ EBSD system. The acquired EBSD orientation map was further processed using the TSL OIM analysis software.

EBSD orientation maps of 17-4PH as-built and solution-treated samples are shown in Figure 1a and $1 \mathrm{~b}$. A non-uniform microstructure is exhibited for the as-built sample composed of elongated coarse martensite laths, up to $100 \mu \mathrm{m}$ in length and aligned roughly parallel to the build direction, and fine equiaxed grains along the martensite lath boundaries. The corresponding EBSD phase map indicates that the retained austenite grains are all located in the fine-grained regions. The solution-treated 17-4PH AM sample exhibits a much more uniform martensitic microstructure. The martensite grain size measured by EBSD is refined from $\sim 22 \mu \mathrm{m}$ in the as-built sample to $\sim 2.8 \mu \mathrm{m}$ in the solution-treated sample. EBSD orientation maps from solution-treated conventional 17-4PH samples also exhibit a uniform martensite microstructure, as shown in Figure 1c. However, the martensite laths are much coarser than those in the solution-treated AM sample. It is well known that the martensite transformation occurs within the prior austenite grains, and so the size of these grains has a significant influence on the martensite lath size. The prior austenite grain boundaries in the EBSD orientation map can be obtained approximately by thresholding the grain boundary misorientation, as shown in Figures $2 \mathrm{a}$ and $2 \mathrm{~b}$. The AM sample has a much finer prior austenite grain size. The formation of such a fine-grained prior austenite is attributed to Zener pinning of the grain boundaries by fine non-metallic inclusion particles in the AM as-built sample, as shown in Figure 2c [3]. 


\section{References:}

[1] H. K. Rafi et al, J. Mater. Eng. Perform, 23 (2014), p. 4421.

[2] S. Cheruvathur, E. A. Lass, C. Campbell, JOM, 68 (2016), p. 930.

[3] This work was supported by a research grant from FEI. The microscopy studies in this paper were performed using the facilities in the UConn/FEI Center for Advanced Microscopy and Materials Analysis (CAMMA).

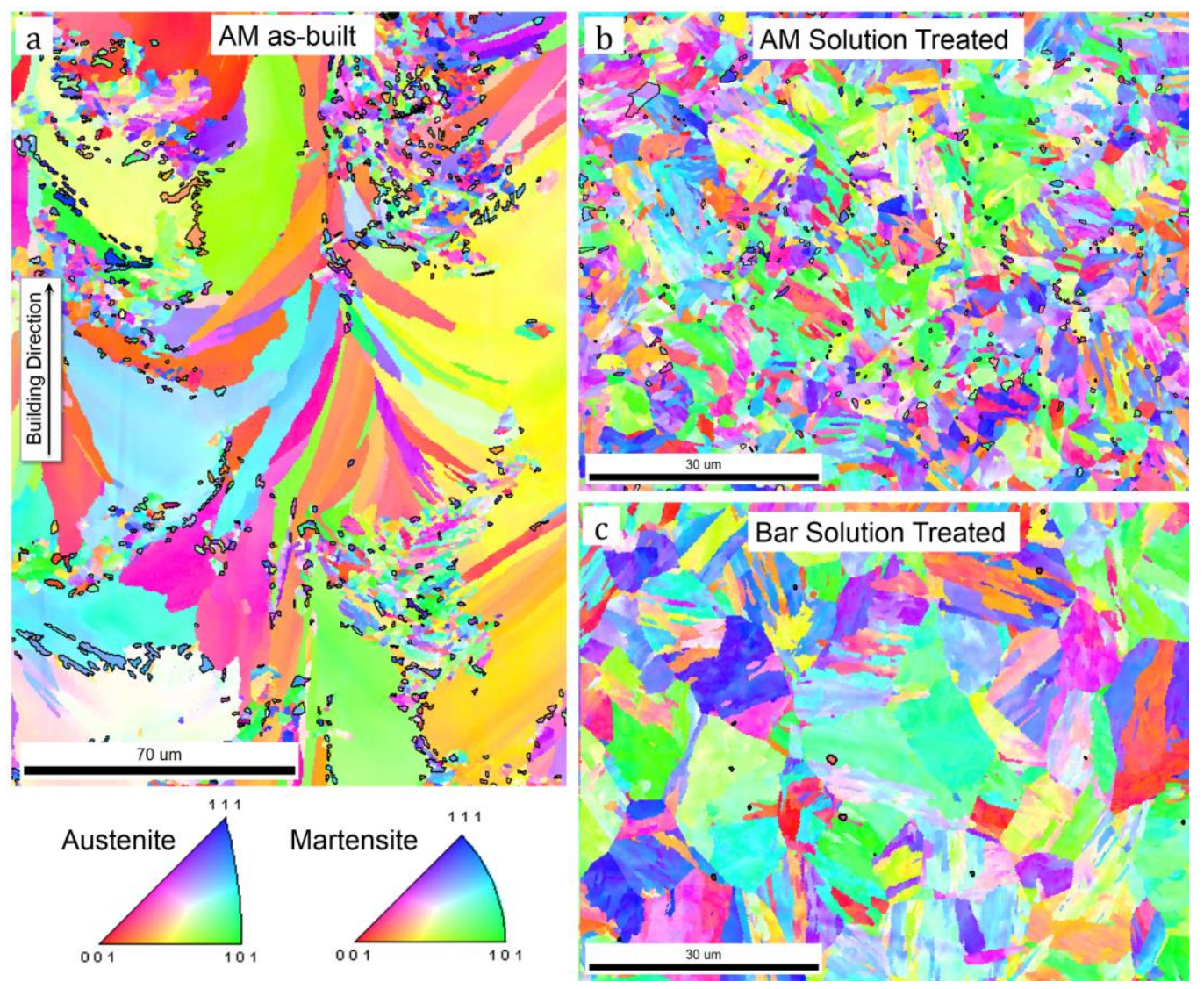

Figure 1. Figure 3: EBSD orientation map of (a) as-built 17-4PH AM part, (b) solution treated 17-4PH AM part, (c) solution treated 17-4PH bar. Austenite/Martensite phase boundaries are highlighted in black color.
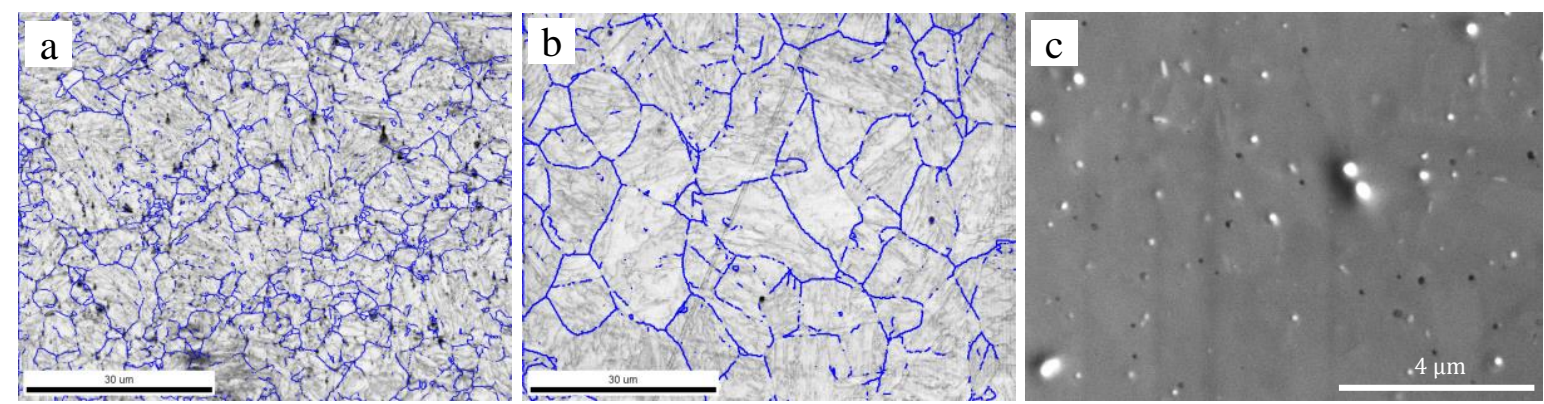

Figure 2. Prior austenite grain boundary maps of (a) solution-treated 17-4PH AM part, (b) solutiontreated 17-4PH bar. (c) SEM images of non-metallic inclusions in the as-built AM part. 